\title{
VIEWPOINT
}

\section{Dealing with difficult authors}

\author{
Pippa Smart \\ PSP Consulting, Oxford, UK; Editor in Chief, Learned Publishing; EASE president, 2018-2020 \\ pippa.smart@gmail.com; ORCID:0000-0002-5528-4704
}

DOI: 10.3897/ese.2020.e52201

This online publication has been corrected (DOI: 10.3897/ese.2020.e58964). The original publication: Smart P. Dealing
with difficult authors. European Science Editing 2020;46. DOI: 10.3897/ese.2020.e52201 was published on 29 April 2020.

\begin{abstract}
There is considerable literature about the responsibilities of authors and editors in regard to ethics and integrity but there is little information on how to manage editor-author relationships when serious disagreements occur and one party starts to behave in an unacceptable manner. This article is based on a recent experience and presents some thoughts and suggestions for editors on how to manage relationships with authors when the authors start to behave badly.
\end{abstract}

Keywords: Communication, Conduct, Editors, Authors, Ethics

There is considerable literature relating to the responsibilities of editors and publishers in their dealings with authors (eg COPE and ICMJE guidelines) ${ }^{1,2}$ and likewise there is considerable literature about research ethics and the issues around authorship (see RetractionWatch) ${ }^{3}$ including informal guides on how to lodge appeals (for example IOP advice). ${ }^{4}$ However, there is little or no reporting of the success of appeals, ${ }^{5}$ or the manner in which authors and editors correspond, with the exception of the cases submitted to the Committee on Publication Ethics (COPE) for mediation - see their website, https:// publicationethics.org/guidance/Case. A recent experience with an author whose submission was rejected by Learned Publishing has led me to reflect on our experiences and offer suggestions for other editors who may encounter similar conflicts.

\section{The case story}

Learned Publishing received an article which was evaluated before sending to reviewers, at which point several problems emerged. The main problem was not the subject (which was of interest), but the way that the article had been presented, which led to the decision to desk reject it before review. Since the subject was of interest, the author was invited to revise and resubmit the article with supporting evidence for the assertions, written in a more professional, dispassionate tone with more balanced arguments.

Several months later the author resubmitted nearly the same article. The author had made no changes to the unprofessional tone; instead, countless supporting files were appended which claimed to support the article's assertions. Although my concerns remained regarding the article's suitability, I nevertheless sent it to two reviewers. To the credit of both reviewers, they provided detailed, objective reviews with suggestions for the author, although both recommended that the article was not suitable for publication.

Given this feedback, and in light of the fact that the author had already been invited to revise the original submission but had failed to do so, I made the decision to again reject the article. This is when the problems started. Within a few weeks after rejecting the article, the author sent me a lengthy email complaining about the decision and making unfounded accusations. The email concluded by saying that the author was considering an appeal. As we are willing to reconsider decisions where authors feel they have justification, the author was sent a short email saying that an appeal process was available and that the author was welcome to submit one.

An appeal was duly received which did not challenge the reviewer comments or the rationale for our decision but instead listed various accusations against me as Editor in Chief. As per our procedure, the article was sent to another member of our editorial team and discussed between two editors, and it was agreed that the original decision of rejection was correct. As expected, the author was very unhappy with this decision, and turned next to emailing members of the editorial board and our parent organisation, as well as posting allegations of misconduct on social media.

\section{Presentation versus content}

The root of the problem with this author was that our decision was based on the submitted article and not the subject of the article. The author was convinced that our reason for rejection was the subject of the article, rather than its construction and presentation. This raises an interesting conundrum for editors. When making a decision on any submission, are we judging the article (ie the presentation), or are we assessing the underlying research? In many cases the two are combined - in other words, both the research and the presentation are independently good, bad, or in need of revision. However, there are also many cases where the research is valid, but the presentation of the article makes it unpublishable. An obvious example of this is where the author is unable to cogently explain the research. The other end of the spectrum is where the article appears to be valid because it is presented in an authoritative, well-written and reported style - however the underlying research is flawed. Sadly, these articles are often only discovered after publication.

Without repeating experiments and reviewing all data in detail, it is often impossible to validate the underlying research, and so 
we must rely on the honesty of authors. Editors and reviewers can only, usually, check the reporting and methodology for sense. The growing requirements to make data available help with this challenge, since the presentation of datasets should encourage more honesty and enable greater validation - although whether reviewers have the time or competence to check the data is not assured across all journals. There are also issues of editorial and reviewer bias that may have some influence, since there is evidence of editors selecting against articles that report negative results or challenge their own views. ${ }^{6}$

It is entirely reasonable for an editor to make a decision to reject an article without reference to the underlying research (because the reporting is obviously inaccurate for example); however any acceptance decision must ensure that the underlying research has been evaluated as far as possible to ensure it is valid and well done.

\section{Sympathising with the author}

Whilst there is no need to delve into the psychology of why authors complain or are abusive, it is part of an editor's role to understand the motivations that drive authors to submit, to publish, and sometimes to complain about the process. Authors have their own pressures that mean they may write without thinking of the implications. It is also important to remember that editors have a privileged position, and with power also comes responsibility. It is easy to reject articles and ignore the effect of this decision on the authors. However, rejection can have a large impact on an author personally, and can potentially risk their next pay rise, their opportunity to obtain tenure, or the precedence of their research. Therefore, no decision must be taken lightly and without due consideration. In this case study, the author is very frustrated that we will not publish their findings and thinks there is a moral imperative for us to do so because of the subject that has been investigated.

Bearing in mind the power imbalance between editors and authors, it is also important to allow authors to appeal rejection decisions - because any decision may have been incorrect (and rejected papers are often published elsewhere, see Docherty and Klein). ${ }^{6}$ The likelihood of decisions being overturned after appeal appears to be low, and some authors have a bad experience of such appeals. ${ }^{8,9}$ However, most resources that advise authors on how to respond to rejection caution authors to always be polite, for example see Kallis. ${ }^{10}$

\section{Dealing with abuse}

Fortunately, editorial communications with Learned Publishing authors are usually cordial and often collegiate. However, in this case, the author's emails were found to be abusive and unprofessional, and we (myself and the North American Editor) decided it was important to ignore the tone of the communications and to ensure that we continued to act with integrity. Whatever the motivations of the author, and despite the upsetting discourse, we endeavoured to maintain a professional tone in our limited correspondences. This is advocated by our publishing organisation Wiley, ${ }^{11}$ and helpful advice for dealing with abusive emails can also be found online. ${ }^{12}$

The author also contacted several members of the editorial board, and together we agreed to avoid any personal engagement or argument with this author, which I believe would have inflamed the situation. We agreed that it was not necessary to reply to each email, and we also agreed to ignore the social media accusations. In all emails to the author we ignored personal comments or those which were unrelated to the appeal and kept our emails brief.

We also felt it was important to act transparently and to keep the entire editorial board, our publisher (Wiley) and our parent organisation (the Association of Learned and Professional Publishers, ALPSP) fully informed of what was happening. This provided a point of validation and ensured that all stakeholders agreed with our decisions and actions. We sought their opinion on how to respond at each stage and, although there was some debate on certain details, we found it important to seek opinions and to achieve consensus where possible. Ultimately, the editor must make the final decision of how to respond to authors, as the responsibility for publishing decisions lies with the editor and not the publisher. (With the exception of any area which may have legal implications.)

We are lucky to have the support of both parent and publishing organisations. Equally, I am lucky to have a supportive editorial team - this would have been a much more difficult situation if I had not been able to discuss it with colleagues.

\section{Summary}

The recent months have proved a learning experience, and one which I hope other editors don't undergo. However, they have revealed some important lessons that I feel are worth passing on to other editors. Note that these recommendations are only based on our experience and should be adapted for each journal's own circumstances.

- Firstly, it is important that editors are careful to make all decisions to publish or reject after due consideration of both the article and the research, and to make such decisions objectively.

- Next, all editors must be willing to reconsider any rejection decision if the author appeals - we can all make mistakes.

- If an author makes accusations either directly or via social media, do not respond immediately, since the first response tends to be too emotional. You can take a reasonable time to ensure that your response is appropriate.

- In the event of any problems, liaise with your editorial team, your publisher and your parent organization to keep them informed: but take the lead in how to respond since publishing decisions are your responsibility (unless they have legal implications).

- Less is more. Don't feel that you need to write long explanations; keep focussed on the important and factual issues - if you become defensive it may undermine your arguments.

- Do not feel you need to defend yourself, simply respond to the facts (this is so important I felt it was worth repeating).

- Do not reply to personal attacks on social media, or if you do so, be very careful of how you respond since it is likely to inflame the situation rather than calm it down.

- Do not become upset by personal attacks; it is important not to let yourself be undermined by people who have no regard for professional, civil communication.

\section{Competing interests}

Pippa Smart was President of the European Association of Science Editors from June 2018 until July 2020. Pippa also owns her own company, PSP Consulting, in Oxford, UK. 


\section{References}

1 Horton, R. A new ombudsman. Lancet 2001;357(9257):656. Doi: https:// doi.org/10.1016/S0140-6736(00)04153-2

2 Teixeira AAC, da Costa MF. Who Rules the Ruler? On the Misconduct of Journal Editors. Journal of Academic Ethics;2010;8:111-128. doi: https:// doi.org/10.1007/s10805-010-9107-y

3 RetractionWatch. Journal that published bogus chocolate study delisted from open access directory. 25 August 2015. https://retractionwatch. com/2015/08/25/journal-that-published-bogus-chocolate-study-delistedfrom-open-access-directory/ (Accessed 11 March 2020).

4 IOP. Appealing against a rejection from our journals. https:// publishingsupport.iopscience.iop.org/questions/appealing-against-arejection-from-our-journals/ (Accessed 12 March 2020).

5 Dambha-Miller H, Jones R. An appealing prospect? A survey into the numbers, outcomes, and editorial policies for appeals of rejected biomedical manuscripts. Learned Publishing 2017;30:227-231. doi: https:// doi.org/10.1002/leap.1107

6 Matías-Guiu J, García-Ramos R. Editorial bias in scientific publications. Neurología (English Edition) 2011;26(1):1-5. doi: https://doi.org/10.1016/ S2173-5808(11)70001-3
7 Docherty A, Klein AA. The fate of manuscripts rejected from Anaesthesia. Anaesthesia 2017;72:427-430. doi: https://doi.org/10.1111/anae.13829

8 Gøtzsche P, Sørensen A. The Review on Antidepressant Withdrawal That Cochrane Won't Publish. Weblog, Mad in America, 11 February 2011. https://www.madinamerica.com/2020/02/review-cochrane-wont-publish/ (Accessed 11 March 2020).

9 ResearchgGate. When should you challenge an editor's decision to reject a paper? 11 November 2013. https://www.researchgate.net/post/When_ should_you_challenge_an_editors_decision_to_reject_a_paper (Accessed 11 March 2020).

10 Kallis, G. My paper was rejected - what do I do now? 24 April 2019. http:// howtowriteanacademicpaper.com/paper-rejection.html (Accessed 11 March 2020).

11 Wiley. Communicating with Authors. https://authorservices.wiley.com/ editors/editorial-office-guidelines/author-communication.html (Accessed 11 March 2020).

12 Ostap. How to Reply Professionally to a Rude Email and Cover Your Ass. https://newoldstamp.com/blog/how-to-reply-professionally-to-a-rudeemail-and-cover-your-ass/ (Accessed 11 March 2020). 